\title{
Computer Simulations In Buildings: Implications For Building Energy Performance.
}

\author{
Nimlyat, P. S., Dassah, E. and Allu, E. L. A. \\ Department of Architecture University of Jos
}

\begin{abstract}
The goals for achievingbetter performance of buildings need more innovative use of computers than a subjective assessment. This paper is a review of the literature about the use of computer simulation in building design and construction. This study examines the types and good examples of computer simulation. The literature review indicated that although computer simulations cannot completely replace the building fabric and components, they offer several benefits both for the building and its environmental performance. This study suggests that the successful use of computer simulation in assessing the energy performance of buildings depends on how, professionals integrate and use it in the design phase and building lifespan. Computer simulation can be employed at the building design phase and also on building in use. The appropriate role of computer simulation is its use to optimize the design of building components and service systems. This is applied according to their requirements for indoor air quality while achieving energy savings in the building. Computer simulations in buildings make it possible to examine in detail a number of solutions for the building geometry and construction, as well as its design and operation. This study also implied that computer simulations have high potentials of significantly increasing the energy efficiency of a building while also providing enhanced human comfort. Computer simulation has, therefore, become a necessary tool that should be integrated into the architectural curriculum in order to achieve sustainable building performance measurement.
\end{abstract}

Keywords: - Computer Simulation, Energy Performance, Energy Saving, Energy Efficiency, Performance of Buildings

\section{INTRODUCTION}

The use of computer is beyond word processing, and one of such computer application is simulation. The Oxford English Dictionary describes simulation as a means of initiating system performance by means of an analogous model, situation or apparatus, either to gain useful information or to train personnel.Fishwick(1995), describes a computer simulation as "...the discipline of designing a model of a real or theoretical physical system, executing the model on a digital computer and analyzing the execution output". On the other hand, Laurillard(1993) states that, "a computer-based simulation is a program that embodies some aspect of the world, allows the user to construct inputs to the model, and displays the result". Computer simulation is a branch of applied mathematics that is widely used by various disciplines. The different uses of computer simulation in various systems are classified as continuous vs. discrete, deterministic vs. stochastic or dynamic vs. steady state (Tasli and Ozguc, 2001). Development in computer science has led to the use of simulation in solving various problems, which had been difficult to handle, much more cost efficient and less time consuming, than experimental study (Richard, 2010). The need for efficiency in all the life cycle of a building is a primary concern ofdevelopers, city planners, andpromoters of standards and certifications like LEED, EnerGuide etc., who is now using an incentive-based approach to achieving greater efficiency (Vital Engineering).

A computer simulation can be set into different roles such as; analysis, invention, research, teaching, training and entertainment. Simulations enhance the possibility of theoretical development (Stiff and Wilensky1), tools for logical survey (White, 2000), and problem solving experiences (Howse, 1998). Computer simulation visualizes a system that does not yet exist in order to achieve the best possible outcomes. The behavior or capability of a building system is determined with the use of computer simulation. Another aspect where computer simulation technology has successfully been used is on the World Trade Centre collapse in New York and new earth-penetrating-weapons (Lu et al., 2004). The use of computer simulations in buildings gives professionals in the built environment opportunity to visualize a building interaction with its components and environment to interact with it. Simulation techniques in buildings make it possible to study in detail a number of solutions for the building geometry and construction, as well as its purpose and operations. The application of computer simulation programs can increase energy efficiency in buildings. According to the EPSR (1998), the application of an integrated simulation program was able to minimize investment and operational costs, reduce cooling energy and building modifications and also, a reduction in the over-steps of the required 
indoor air temperature. However, the application of computer based simulation in the building industry has gained wider acceptance only in the last few years.

The integration of smart building design features into buildings can significantly increase the energy efficiency of the building while also providing enhanced human comfort. This can be through the use of intelligence such as simulations to improve the performance of the building fabrics. The primary aim of this paper is to review the role of computer simulations in buildings. The focus for this study is to find a way of enhancing the environmental and energy performance of buildings with computer technology both in the design and operational phase of the buildings. There is also a need to evaluate the potential use and benefits of computer simulations in building energy performance measurement.

The purpose of this study is to encourage the use ofinnovation in computer simulation techniques as utilized in building design and construction. The objectives of this study are twofold;

1. To bring to the knowledge of architects and engineers skills and awareness of the available computer simulation tools, evaluation methods, and computer-based problem solving.

2. To provide information that meets the requirements of building professionals in relation to computer simulations for buildings and services system design and operation.

This study consists of three parts: the first part describes computer simulations; the second section reviews the benefits of computer simulations in buildings, and the last part makes connections with the building energy performance.

\section{COMPUTER SIMULATIONS}

Computer simulation has become a useful part of modelling natural systems as a means of understanding how such systems operate in the fields of physics, chemistry and biology for quite some time now. Simulation is essentially a method for conducting highly controlled statistical experiments on a model of a real system using computer programs (Sahlin, 2000). A simulated system can be well understood by statistically analyzing the application model results. Simulation, unlike analytical modelling, is less an abstract model or mathematical, and the link between the model and the system can be easily conceptualized. Computer simulation involves creating a computer software based model of a system in order to understand the behavior of the system (Sahlin, 2000).

Isken(2003) identifies 3 broad classes of simulation modelling approaches. These are discrete event simulation, Monte-Carlo simulation, and Continuous simulation.In discreet event simulation, systems are modelled as a collection of discrete entities, locations, and resources which interact within a period. This model is not used in building simulation but commonly used for call centers, computer and communication networks.Monte-Carlo simulation, on the other hand, interprets the impact risk and uncertainty in financial, project management, cost, and other forecasting models. Monte-Carlo simulation is a method that can be used to obtain numerical solutions to problems that cannot be analyzed analytically (MATHwORLDTM). The working of a Monte-Carlo simulation involves the selection of a random value for each task based on the range of estimates (www.riskamp.com). The model of these randomly selected values is calculated and repeated severally, and the results are used to identify the probability of reading various results in the model. MonteCarlo simulation model has a wider usability; in environment, energy, engineering, finance, project management, manufacturing, oil and gas, transportation and so on.Continuous simulation according to the Wikipedia is a computer model of a physical system tracking its response continuously over time according to differential equations. While discrete event simulation is based on the system behavior only at discrete points, continuous simulation behavior changes at uncountable points in time (Wikipedia). The application of continuous simulation is mostly in hydrology and hydraulics.

Computer simulation is necessary especially in buildings because of its numerous advantages. Harrell et al (2000) in their written report stated some importance and demand for simulations to achieve results in a variable system. Simulation is versatile enough to model any system in order to determine its behavior over time and to present results that are easy to grasp and communicate. Simulation runs a real system that is less expensive, less time consuming and also providing information on multiple performance measures Simulation involves different stages that are necessary for modelling a system. And these are;

1. Problem identification and prioritization

2. Objective setting and project planning

3. Conceptual model design

4. Model life cycle design

5. Data collection methods

6. System modelling and development

7. Validation of the model

8. Experimental design and analysis

9. Production runs of any size 
10. Analysis and outcome reporting

According to studies conducted by different researchers (Liu, 2003; Guven, 2013; Richard, 2010;Novak et al., 2013), computer simulation have both advantages and disadvantages. Some of these advantages are listed as follows;

1. It provides the flexibility to evaluate different alternatives for the same model.

2. The system is dynamic with much better control over experimental conditions.

3. It can compare to other process support techniques.

4. A different performance indicator of a system can be observed and analyzed

5. It can be used to measure the performance of even a system that is nonexistence.

Some disadvantages of the application of computer simulation as a tool for performance measurements are;

1. The data regarding the processing and demand information and operation rules are not readily available in the design phase.

2. Simulation project can contain a risk factor in a model which cannot be fully anticipated at the initial stage of the design.

3. Inaccurate result is eminent if data entered into the model are also inaccurate.

4. There are additional factors that can affect the simulation outcome since running it in a monitored environment is not the same as a real world situation.

\section{COMPUTER SIMULATIONS IN BUILDINGS}

The development of tools to model and simulate the different aspects of building performance were as a result of the need for sustainability and preservation within the built environment triggered by technological advancement (Jain et al., 2001). The evolution of building simulation programs has made it possible to simulate complex interaction of building components and systems, as compared to, simple energy consumption calculations (Nakahara et al., 1999). Computer simulation is becoming a required element in construction and retrofits because, it is a powerful tool for comparing alternative designs and achieving an optimal combination of factors. Buildings optimized and "tuned" with computer simulations save money and increase the health and wellness of occupants, and operate optimally for a long time (Vital Engineering). Computer simulations are being used to evaluate building energy performance in different countries of the world, and to demonstrate compliance to building energy standards. Computer modelling optimizes the design of the building and its service system according to the requirements for indoor air quality while keeping energy consumption at minimum levels (Bartak et al., 2000).

Building a simulation model requires detailed exploration, documentation and explanation of the process involved in the system being studied (Isken, 2003). The application of computer simulation in buildings is to simulate various situations that will affect the building energy performance results, such as the building use patterns, building shape and materials, and the weather condition. Computer simulation can be used for both design support of a new building and also for the optimization of the heating, ventilation and air conditioning control strategy during operation of the completed building.

\section{APPLICATION OF COMPUTER SIMULATIONS IN BUILDINGS ENERGY PERFORMANCE MEASUREMENT}

The evaluation of buildings energy and environmental performance has expanded considerably into engineering practice. One of the reasons for the analysis of the energy performance of buildings is for comparison of energy use among nations, regions, individual buildings or systems within a building (Barley et al., 2005). According to Lain et al (2008), sustainable buildings in terms of energy can be achieved through the evaluation of the interrelationship between building components and the environmental factors. Computer simulation can be used to investigate performance risks and problems in the energy performance of the buildings; particularly in common areas of risk such as; lighting control, equipment control and supplementary air-conditioning operation. The reliability of simulation results depend mostly on the availability of input data to develop and output data to calibrate the computer model. In any case, given the same input and output information, the result from computer simulation will be as reliable as or more so than those produced by any other method, especially in determining the amount of energy savings (Huang, 2012). With the trend toward energy efficient building designs, energy simulation programs are being widely used in the design process, to assist architects and engineers to determine, what design alternative save energy and is cost efficient (Tianzhen et al., 2008).

Many tools have been developed to analyze energy performance in different ways, at different levels of effort and precision, and at different stages in the life of a building (Barley et al., 2005). Energy efficiency and environmentally friendly buildings have been designed, and their performance predicted with the aid of different computer simulation models. This computer modelling techniques is being used to test the effect of different environmental systems on a building's energy-efficiency. The application of these building energy analysis 
programs, however, depends to a large extend on how well the programs predict actual energy usage in a building. Furthermore, to what level of sophistication and details is the program in achieving a reasonable estimate of the projected energy use? (IOWA Energy Centre, 2012)

Computer-based building energy simulations are appropriate for constructions in which;

1. A building energy management or control system is specified

2. The degree of interaction among multiple measures is either unknown or too difficult or costly to evaluate.

3. The measures involve improvements that primarily affect building loads.

The growth in usage and importance of computer simulation has led to its application in the design, operation and maintenance processes of buildings as a required tool to achieve energy efficiency. Computer simulations have been used as the most logical and dependable method for determining energy savings in buildings. The simulation of the energy performance of buildings requires the analysis of hundreds of building components and the periodic sampling of their performance over some time interval. This time interval may be as long as several years or as short as a single hour. A building energy simulation program is no less and no more than an hour-by-hour calculation of a building's energy use. This process uses complex thermodynamics EQUA Solutions that take into account the constant changes in the weather and the building's internal conditions, and, the dynamic response of the building and space conditioning system to such changing condition (Huang, 2012).

Today there are buildings which are referring to as intelligent buildings. An intelligent building has particular intelligent-like capabilities to respond to pre-programmed stimuli to optimize it's mechanical, electrical, and enclosure systems (Yeang, 1996). An intelligent building understands its configuration, anticipate the optimum dynamic response to prevailing environmental stimuli, and trigger the appropriate physical reaction in a predictable manner. According to Ali and Armstrong (2006), intelligence can be used to improve the performance of the building fabric by integrating smart building design features into new construction, which can significantly increase the energy efficiency of the building while also providing enhanced human comfort. This can be achieved by the application of simulation tools in the building.

\section{COMPUTER SIMULATION PROGRAMS/TOOLS FOR BUILDING ENERGY PERFORMANCE MEASUREMENT}

Energy programs are primarily designed to predict the annual energy consumed by a structure in terms of Building Total Usage (BTUs), or pollution avoidance. However, few buildings benefited from energy analysis in the past. Today energy analysis tools are becoming more common and are being applied earlier in the design process (Richard, 2010). Different simulation programs may have different software design, use different algorithms to model building and energy systems, and may require different user inputs on describing the same building envelope or HVAC system component. Below are descriptions of some of the computer programs used in simulating buildings to measure their energy performance.

\subsection{BLAST (Building Loads Analysis and System Thermodynamics)}

This simulation tool performs hourly simulations of buildings, air handling systems, and central plant equipment in order to provide mechanical and architectural engineers with accurate estimates of a building's energy needs. The zone models of BLAST that is based on the fundamental heat balance method is the industry standard for heating and cooling load calculations. It can be used for the evaluation of high-potential, costeffective energy efficiency project in existing buildings. The BLAST program uses detailed heat balance algorithms that allow for the analysis of thermal comfort, and other factors that cannot be analyzed in programs with less rigorous zone models. It however requires a high level of expertise to operate.

\subsection{DOE-2}

This is an hourly, whole-building energy analysis program for calculating energy performance and lifecycle cost of operation. It can also be used to analyse energy efficiency of given designs or efficiency of new technologies. Other uses could include utility demand-side management and rebate programs, development and implementation of energy efficiency standards and compliance certification and train a new corps of energy efficiency conscious building professionals in architecture and engineering schools. The DOE-2 is widely recognized as the de-facto standard. It has the advantage of detailed, hourly, whole-building energy analysis of multiple zones in buildings of complex design (EQUA Solution, 2012).

DOE-2 is a widely used and accepted freeware building energy analysis program that can predict the energy use and cost for all types of buildings. DOE-2 uses a description of the building layout, constructions, operating schedules, conditioning systems (lighting, HVAC, etc.), and, utility rates provided by the user, along with weather data, to perform an hourly simulation of the building and to estimate utility bills. 


\subsection{VisualDOE}

This is a windows interface to the DOE-2 energy simulation program. Through the graphical interface, users construct a model of the building's geometry using standard block shapes or using a built-in drawing tool (EQUA Solution, 2012). DOE-2 has an interface with platforms which includes, library of constructions, fenestrations, systems, and operating schedules, and the user can also customize it to fit into other elements. The program assigns default values for parameters based on the vintage and size of the building. VisualDOE is especially useful for studies of the building envelope and HVAC design options, with the possibility of specifying up to 20 alternatives for an individual project. The VisualDOE dramatically reduces the time needed to build a DOE-2 model and can be used to import CADD data to define thermal zones, but is relatively expensive.

\subsection{EnergyPlus}

EnergyPlus is a new generation simulation program built upon the beauties of both DOE-2 and BLAST and adds new modelling features beyond the two programs. EnergyPlus includes innovative simulation capabilities that are not time consuming. It also has integrated modular system simulation modules that are tailored to facilitate third party interface.

EnergyPlus does sub-hourly calculations and integrates the load and system dynamic performance into the whole building energy balance calculations, which can provide more accurate simulation results (Tianzhen et al., 2008). EnergyPlus has accurate, detailed simulation capabilities which can run on Windows, Macintosh, and Linux platforms, but it is very difficult to use without a graphical interface. Several interfaces and utilities for EnergyPlus are available, including EP-Quick which creates an EnergyPlus input file based on a broad range of zone templates (SklogWiki). EnergyPlus is a whole building energy simulation program that engineers, architects, and researchers use to model energy and water use in buildings. Modelling the performance of a building with EnergyPlus enables building professionals to optimize the building design to use less energy and water (Energy Plus). With DOE-2's limitations in modelling emerging technologies, more and more modellers have begun using EnergyPlus for their simulation needs, especially for LEED green building designs and low or net-zero energy buildings.

\subsection{Computer program CAPAS31}

This is a computer simulation method using a software tool to analyse the energy performance of buildings through the use of an hour-by-hour transient thermal network simulation (EQUA Solution, 2012). This simulation method has been validated for the accuracy of its results against other computer models and functional buildings. The software input format is flexible from where one can choose simulation points, and has a range of output reports, which include annual and peak-annual cooling and heating loads, monthly and hourly energy balance reports.

\subsection{ECOTECT}

It is one of the most popular simulators among its own types, and its day lighting evaluation can be considered as the most consistent application (Khaled, 2007). The ECOTECT is a complete building design and environmental analysis tool that covers the full range of simulation and analysis functions, required truly, to understand how a building design will operate and perform (Ecotect). US department of energy accentuates that it provides essential analysis feedback from even the simplest sketch model (US Department of Energy). ECOTECT simulation program progressively guides the user as more detailed design information becomes available.

\section{7 eQUEST}

This is the most widely use building energy simulation program in the world which contains a built-in capability to manage rule set. eQUEST is a freeware building energy analysis tool that is easy to use and provides professional-level results with an affordable level of effort. The design of eQUEST enables a comparative analysis of building designs and technologies even with little experience in the "art" of building performance modelling. The eQUEST is comprised of a combination of schematic and building design development wizards, an energy efficiency measure (EEM) wizard, and a graphical results display module with a complete up-to-date DOE-2 building energy use simulation program (eQUEST).

One of eQUEST's particularly useful extensions to the DOE-2's capabilities is the implementation of dynamic, intelligent defaults. Every input specification has an industry standard default value that is dynamically determined based on the user's previous entries (Ziai, 2006). eQUEST's intelligent default system boosts usability by making the simulation setup faster and independent of level of expertise, even when the user simply has no knowledge of them,. 


\subsection{HAP (Hourly Analysis Program)}

A system design tool and an energy simulation tool in one package. It Uses a Windows-based graphical user interface and 32-bit software. HAP's design module uses a system-based approach that tailors sizing procedures and reports to the type of system being considered (EQUA Solution, 2012). HAP's energy simulation module performs a true 8,760 hour energy simulation of building heat flow and equipment performance. The HAP program compares energy consumption and operating costs of design alternatives but, however, have a limited ability to calculate interactions between some strategies.

\subsection{TRACE Load 700}

TRACE Load 700 uses ASHRAE-standard algorithms and enables non-sequential data entry that encourages "what if" analysis. You can edit building construction details in any order and easily change the building model as the design progresses (SklogWiki), and export the completed project file to TRACE 700 for a detailed energy analysis. This tool has a window-based operating environment that requires a simplified input method and models more than 25 types of air distribution systems.

\section{CONCLUSION}

The literature review suggests that computer simulation can play significant roles in building designs and operations either in energy performance or occupancy comfort. Computer simulations are essentials for simulating buildings that are impractical, expensive, impossible, or too dangerous to run. This can contribute meaningfully to conceptual change, and solving problems associated with building performance. Computer simulations provide the architect or engineer an opportunity to observe a real world experience around a building and interact with it.

Computer simulation provides an environment where buildings can be analyzed even at the design stage to measure how they will perform after construction. This study implied that the success of computer simulation as use in building energy analysis depends to a large extent on how they are use and monitor.

\section{REFERENCES}

[1] Fishwich PA(1995).Simulation Model Design and Execution. Prentice Hall Inc.: 1995.

[2] Laurillard D (1993). Rethinking University Teaching a Framework for effective use of Educational Technology. Routledge.

[3] Tasli S, Ozguc B (2001). Dynamic Simulation in Virtual Environments an Evaluation Tool for Architectural Design. Architectural Science Review, 44 (2): 139-144.

[4] Richard P (2010). Energy Analysis Tools. Whole Building Design Guide (WBDG). A Program of the National Institute of Building Sciences 2010.Available via www.wbdg.org/resources/energyanalysis.php. Retrieved 14/06/2012

[5] Vital Engineering.The Case for Computer Simulation of Buildings.Vital Engineering Corporation Sherwood Park, Alberta, Canada. Available via, www.vitaleng.com, Retrieved 03/06/2012

[6] Stiff M, Wilensky1 U (2003). Connected Chemistry - Incorporating Interactive Simulations Into The Chemistry Classroom. Journal of Science Education and Technology.12:280-302

[7] White B,Frederiksen J (2000). Technological Tools and Instructional Approaches for Making Scientific Inquiry Accessible to all. In: Jacobson M, Kozma R, editors. Innovations in Science and Mathematics Education: Advance Designs for Technologies of Learning. Mahwaj NJ; Lawrence Erlbaum Associates, pp. 321-359.

[8] Howse MA (1998). Student Ecosystem Problem Solving Using Computer Simulation.Washington DC, Office of Educational Research and Improvement. (ERIC document reproduction service No. ED419679)

[9] Lu X, Yang N, Jiang J (2004).Application of Computer Simulation Technology for Structure Analysis in Disaster.Automation in construction, 13:597-606. Available via,www.luxinzheng.net/publications, Retrieved 18/07/2012.

[10] ESP-r (1998).A Building Energy Simulation Environment ESRU Manual. Energy Systems Research Unit. University of Strathclyde. Glasgow.

[11] Sahlin P (2000). The Methods of 2020 For Building Envelope and HVAC Systems Simulation. Will the Present Tools Survive? EQUA SOLUTIONS Simulation Technology Group AB 2000.Available via, www.EQUASolutions.se. Retrieved 23/08/2012

[12] Isken M (2003). Computer Simulation, Available via. http://www.informs-cs.org/wscpapers.html. Retrieved 28/05/2012

[13] MATHwORLDTM.Monte Carlo Method. Available via,http://Mathworld.wolfram.com/ MonteCarloMethod.html Retrieved 8th October 2013.

[14] www.riskamp.com. What is Monte Carlo Simulation. Available via,www.riskamp.com/ files/RiskAMP\%20-\%20Monte\%20Carlo\%20Simulatio.pdf. Retrieved 08/10/2013. 
[15] Harrell C, Ghosh BK, Bowden R (2000). Simulation Using ProModel. Boston, MA: McGraw Hill.

[16] Liu C (2003). Educational computer simulation: Benefits and application.Available via, http://projects.edte.ntwemte.nl/pi/sim/Liu.html, Retrieved 03/10/2013.

[17] Guven U (2013). Modelling and simulation engineering solution, Academia.edu.Available via, www.academia.edu/1709194/modelling_and_Simulatio_in_Engineering_Solutions. Retrieved 03/10/2013.

[18] Nowak A, Rychwalska A, Borkowski W (2013). Why simulate? To develop a mental model, Journal of artificial societies and social simulation, 16(3), 12.Available via, http://jasss.soc.surrey. ac.uk/16/3/12.html, retrieved 03/10/2013.

[19] Jain S, Workman RW, Ervin EC, Collins LM (2001). Analyzing the supply chain for a large logistics operation using simulation, Proceedings of the 2001 Winter Simulation Conference,pp. 1123-1128.

[20] Nakahara N, Yoshida H, Udagawa M, Hensen J (1999). Building Simulation '99. Proceedings of the 6th International IBPSA Conference, 13-15 September 1999. International Building Performance Simulation Association.Available via, http://www.bwk.tue.nl/fago/IBPSA/, Retrieved 11/02/2012

[21] Bartak M, Drkal F, Hensen J, Lani M (2000). Computer simulations - Energy Saving Design Tool. Proceedings of Energy efficiency Business Week EEBW 2000, Seven Prague.Available via, http://www.bwk.tue.nl/bps/hensen/publications/00_eebw_prague.pdf, Retrieved 15/08/2012

[22] Barley D, Deru M, Pless S, Torcellin P (2005). Procedure for Measuring and Reporting Commercial Building Energy Performance. National Renewable Energy Laboratory 2005.Available via,www.nrel.gov/docs/fy Retrieved 26/04/2012

[23] Lain M, Drkal F, Hensen JL M, Zmrhal V (2008). Computer Simulation for Better Air-conditioning and ventilation Design of Industrial Halls. Proceedings of the Central European Regional IBPSA Conference, "Computer Aided Building Physical Modelling" 5th June 2008, pp. 1-4.

[24] Huang J (2012).Using computer simulation to assess energy ad carbon reductions in building CDM projects.Available via,http://cdm.unfccc.mt/stakeholder/workshops/build-fccc/conf.ppt. Retrieved 25/10/2012.

[25] Tianzhen H, Fred B, Philip H, Stephen S, Michael W (2008). Comparing Computer Run Time of Building Simulation Programs. Environmental Energy Technologies Division July 23, 2008. Ernest Orlando Lawrence Berkeley National Laboratory.

[26] IOWA Energy Centre (2012).A Comparison of Building Energy Simulation Software to Actual Energy Use.Available via, www.iowaenergycenter.org. Retrieved 28/05/2012

[27] Yeang K (1996). The Skyscraper Bioclimatically Considered. Academy Edition, London, UK.

[28] Ali MM, Armstrong PJ (2006). Strategies for Integrated Design of Sustainable Tall Buildings: AIA report on University Research. Available via,http://www.aia.org/aiaucmp/groups/ek_public/documents/ pdf/aiap080038.pdf, Retrieved 06/06/2012.

[29] EQUA Solutions.Building Simulation Tools 2012. Available via, http://EQUA Solutions.se.linweb57.kontrollpanelen.se/en/software Retrieved 22/06/2012

[30] SklogWiki.Materials Modelling and Computer Simulation Codes.Available via,www.sklogwiki.org/ sklogWiki/. Retrieved 24/08/2012

[31] EnergyPlus.Available via, www.energyplus.gov. Retrieved 12/09/2012

[32] Khaled SA (2007). Testing Glare in Universal Space Design Studios in Al-Ain, UAE Desert climate and Proposed Improvements, Renewable Energy, 32:1033-1044.

[33] Ecotect.Available via, http://www.squ1.com. Retrieved 15/08/2012

[34] US Department of Energy.Available via, http://www.eere.energy.gov. Retrieved 09/07/2012

[35] eQUEST.Available via, http://www.doe2.com/equest/. Retrieved 12/09/2012

[36] Ziai N (2006). Measuring Building Performance. Energy Efficiency Software Tools.Sustainability and the Built Environment 2006.Available via, http://extension.ucdavis.edu/unit/green_building_and_ sustainability/pdf/resources/measure_bldg_perf.pdf.Retrieved 12/07/2013. 